\title{
Defined Eligibility Criterion Required Response
}

National Cancer Institute

\section{Source}

National Cancer Institute. Defined Eligibility Criterion Required Response. NCI Thesaurus.

Code C93768.

The reply necessary to include/exclude a potential subject on a study. 